\title{
ENFRENTAMIENTOS EN TORNO AL PODER: EL MITO DE ANTÍGONA EN LA DRAMATURGIA ARGENTINA CONTEMPORÁNEA
}

\author{
Confrontations over power: the myth of Antigone in contemporary Argentine \\ dramaturgy
}

\author{
Claudia Elizabeth Lobo* \\ UNT \\ claudinae@yahoo.com.ar
}

Rolando Jesús RochA**

UNT-UNSTA

rjrocha25@gmail.com

\author{
Palabras clave \\ poder; \\ enfrentamientos; \\ Antígona; \\ reescritura; \\ Huertas
}

Keywords
power;
confrontations;
Antigone;
rewriting;
Huertas

\section{Resumen}

En el intento por construir su identidad, cada cultura apela a elementos propios y ajenos, tratando de generar representaciones de sí misma. En el caso de la cultura argentina, entre los elementos no propios se encuentran los que pertenecen a la cultura grecolatina, entre ellos el sistema literario, en el que centramos nuestra mirada. Con diversas finalidades, los autores se apropian de los textos clásicos grecolatinos reelaborándolos y resignificándolos. En este trabajo nos centramos en una reescritura de Antígona de Sofócles: Antígonas: linaje de hembras de Jorge Huertas, dramaturgo argentino contemporáneo, para analizar las relaciones y los enfrentamientos que se gestan en torno al uso/abuso del poder. El traslado de la tragedia griega a la Argentina contemporánea permite tratar una problemática de vieja raigambre, el tema del poder y las relaciones que en torno a él se entablan, con nuevas miradas. Así, la apropiación y recreación de un texto clásico permite ensayar nuevos modos de decir la realidad, siempre compleja y múltiple, dando cuenta del aporte del mundo antiguo al corpus cultural occidental, en general, y argentino, en particular.

\begin{abstract}
In the attempt to build its identity, each culture appeals to its own and foreign elements, trying to generate representations of itself. In the case of Argentine culture, among the non-proprietary elements are those that belong to the GrecoLatin culture, among them the literary system, on which we focus our gaze. For various purposes, the authors appropriate the classical greco-latin texts by re-elaborating and resignifying them. In this paper we focus on a rewriting of Antigone by Sophocles: Antígonas: linaje de hembras by Jorge Huertas, contemporary Argentine playwright, to analyze the relationships and confrontations that are gestated around the use/abuse of power. The transfer of the Greek tragedy to contemporary Argentina allows us to deal with a problem of old roots, the issue of power and the relationships that are established around it, with new perspectives. Thus, the appropriation and recreation of a classic text allows testing new ways of saying reality, always complex and multiple, accounting for the contribution of the ancient world to the Western cultural corpus, in general, and the Argentine, in particular.
\end{abstract}




\section{Enfrentamientos en torno al poder: el mito de Antígona en la dramaturgia argentina contemporánea}

La cultura grecolatina ha sido permanente objeto de apropiación y recreación por parte de otras culturas. A lo largo de los siglos, en un camino hecho de continuidades y rupturas, Occidente se ha acercado de diversos modos al mundo clásico, tanto desde la admiración e intentos de imitación o restauración, como desde el distanciamiento o rechazo.

En el intento por conquistar un lugar en el mundo, las culturas ${ }^{1}$ elaboran representaciones de sí mismas, apelando a elementos propios y ajenos, para construir una identidad que las posicione frente al "otro". La construcción de identidades culturales lleva implícita la noción de dinamismo; se trata de procesos nunca acabados, en elaboración constante, que pueden ser más nítidos en determinados períodos, como las situaciones de crisis.

Así, con diversas finalidades, los autores se apropian de los textos clásicos grecolatinos reelaborándolos y resignificándolos. En este trabajo nos centramos en una reescritura de Antígona de Sofócles: Antígonas: linaje de hembras de Jorge Huertas (2002), dramaturgo argentino contemporáneo, para analizar las relaciones y los enfrentamientos que se gestan en torno al uso/abuso del poder. E1 traslado de la tragedia griega a la Argentina contemporánea permite tratar una problemática de vieja raigambre, el tema del poder y las relaciones que en torno a él se entablan, con nuevas miradas.

\section{Antígona de Sófocles}

La creación de la tragedia en Grecia significó la objetivación en el drama de un conflicto surgido de fuerzas en pugna o de una situación cuya resolución parece imposible. En el caso de la Antígona de Sófocles (442 a.C.), el texto plantea el enfrentamiento de dos posturas vitales antagónicas e irreconciliables, encarnadas en las figuras de Creonte y Antígona: la existencia de una ley y una justicia de naturaleza distinta.

La historia de Antígona se desarrolla en el tiempo lejano del mito. Antígona es una de las hijas de Edipo, el que, víctima de una compleja red del destino, termina asesinando a su padre, casándose con su madre y teniendo hijos con ella. En la versión seguida por Sófocles, que Esquilo recoge en Los siete contra Tebas, después del destierro de Edipo, sus dos hijos, Etéocles y Polinices, acuerdan gobernar Tebas de manera alterna, un año cada uno. Vencido su período, Etéocles niega a su hermano su derecho y lo destierra. Polinices vuelve contra la ciudad para reivindicar su pretensión al trono; ambos hermanos mueren en la batalla. Creonte, su tío, asume el poder y proclama un edicto negando los ritos fúnebres a Polinices. Antígona se encuentra en la circunstancia de tener que sepultar a su

1. Entendemos por cultura, según los conceptos de I. E. Zohar (1999), un polisistema, esto es, un conjunto de subsistemas (la lengua, la historia, la economía, la literatura, la filosofía, etc.) que pueden entablar dos tipos de relaciones: por un lado, intrarrelaciones, es decir, dentro del mismo polisistema cultural; por otro lado, interrelaciones con otros sistemas de otras culturas, tanto sincrónica como diacrónicamente. 
hermano, a pesar del decreto oficial que lo prohibía expresamente por haber atacado la ciudad. Por esta desobediencia, Antígona sufre la pena de muerte, pero Creonte pierde a su hijo y a su esposa.

La obra es el drama de dos personajes antitéticos y en lucha permanente a raíz de sus visiones radicalmente opuestas: Antígona responde a las leyes eternas e inmutables de los dioses, las cuales no pueden ser contravenidas por ninguna autoridad humana; Creonte hace emanar la ley de su propia autoridad.

La cosmovisión de Antígona responde a la idea de que el mundo se rige por un orden superior, respecto del cual el hombre no puede oponerse con decretos que quebranten esa armonía universal. Así lo señala Kitto (1987, p. 243), “el griego jamás dudó ni por un momento de que el universo no es caprichoso: obedece a la Ley y, por consiguiente, es susceptible de una explicación”. Hay en el universo un orden, una básica regularidad que debe ser siempre mantenida, de suerte que la alteración de este orden lleva consigo una reacción contraria que tiende a restablecer el equilibrio roto.

En el drama, Antígona se presenta como una figura que no condice con la mujer histórica de su contexto de producción. No solo realiza acciones heroicas, desafiando la autoridad de la ciudad, sino que no aparece circunscripta al ámbito del oikos. Por el contrario, el personaje se desplaza por la ciudad, sin que esto llame la atención a los ciudadanos y, a pesar de que en el texto hay marcas que reafirman el rol tradicional de la mujer, su conducta en conjunto se aparta de la representación convencional asignada por la sociedad.

Estas desviaciones del esquema consagrado por las pautas sociales atenienses no deben de haber pasado inadvertidas para los espectadores; por el contrario, constituyen un elemento que debe ser tenido en cuenta en la consideración de la tragedia de Sófocles. En efecto, en una ciudad en la que un gobernante promulga decretos en contradicción con las leyes eternas de los dioses, exponiendo a todos al castigo, es justamente una mujer la que restablece el orden, al cumplir, movida por la piedad, con una ley universal mucho más vinculante, la de sepultar a los muertos, ya que "los deudos más cercanos deben al muerto el tributo de un solemne entierro, como primera demostración del piadoso culto que están obligados a rendir a la salvación de su alma” (Rohde, 1948, p. 230).

\section{La reescritura de Antígona de Sófocles en la Argentina del s. XXI}

La Antígona de Sófocles, como tantas otras obras de la Antigüedad Clásica, ha sido objeto de innumerables relecturas, traducciones, transposiciones, interpretaciones y reescrituras que autores de distintas épocas y culturas han hecho de la materia grecorromana (cfr. Hardwick Stray, 2011, p. 1). En el caso de la Argentina, a Antígona Vélez de L. Marechal (1951) y Antígona furiosa de G. Gambaro (1986), se suma Antígonas: linaje de hembras (estrenada en 2001), de Jorge Huertas. Casi 2500 años después de su puesta original tiene lugar una nueva reescritura de la tragedia griega en la que se retoma el conflicto original allí planteado para situarlo en el Buenos Aires actual. Como afirma Leandro Pinkler (2002, p. 11): "El texto de Huertas es una auténtica versión porque recrea -con permanente intertextualidad- el original de Sófocles con audacia tanguera pero mantiene vivo el núcleo filosófico y lo amplía”. 
El conflicto ético encarnado en las figuras de Antígona y Creonte se reactualiza en la obra de Huertas para aludir a hechos de un contexto diferente: la historia argentina reciente. El dramaturgo traslada la tragedia griega a nuestro país, manteniendo casi todas las escenas originales pero introduciendo algunos cambios, como los elementos que sirven para situar la acción en Buenos Aires (la alusión, por ejemplo, al carillón de La Merced, el ágora de Mayo, entre otros) y la introducción de nuevos personajes: el Río de la Plata y la Embalsamada Peregrina.

En el título encontramos una de las diferencias con la obra sofoclea: el nombre de la heroína aparece en plural, resaltado tipográficamente con una "s" mayúscula. A él se agrega el sintagma "linaje de hembras" para sugerir la continuidad ininterrumpida con el personaje de la tragedia griega.

Otra diferencia la constituye el coro que, al contrario de lo que ocurre en la tragedia ática, está íntegramente formado por mujeres, el "coro de hembras", que cobra un marcado protagonismo con sus intervenciones.

Uno de los paratextos que da una de las claves de lectura es el epígrafe de Homero Manzi: "Estoy lleno de voces y colores. Unas veces recogidos en el sonambulismo de la marcha; otras, inventados tras mi propia soledad" (Huertas, 2002, p. 17). Queremos detenernos en dos palabras, "recogidos" e "inventados", que pueden leerse como una síntesis interpretativa de la obra. Por un lado, aluden a la tradición literaria iniciada por el hipotexto clásico y a su reescritura a lo largo de los siglos y, por otro, a los cambios y nuevos significados de acuerdo con las circunstancias socioculturales de la enunciación. "En este sentido la operación realizada por Huertas se inscribe en una cadena de resemantización, en la que el antiguo mito resuena en un aire nuevo"(Pinkler, 2002, p. 10); "el antiguo conflicto ético planteado en el siglo de Pericles vuelve a cobrar sentido como espejo de los nuevos dolores del presente" (Pinkler, 2002, p. 9).

La reescritura del conflicto trágico persigue el objetivo de tratar de interpretar la realidad argentina, signada muchas veces por las luchas fratricidas y por los abusos de poder en distintos momentos de la historia del país. Tal como lo refleja, por ejemplo, un fragmento de uno de los parlamentos de Ismena:

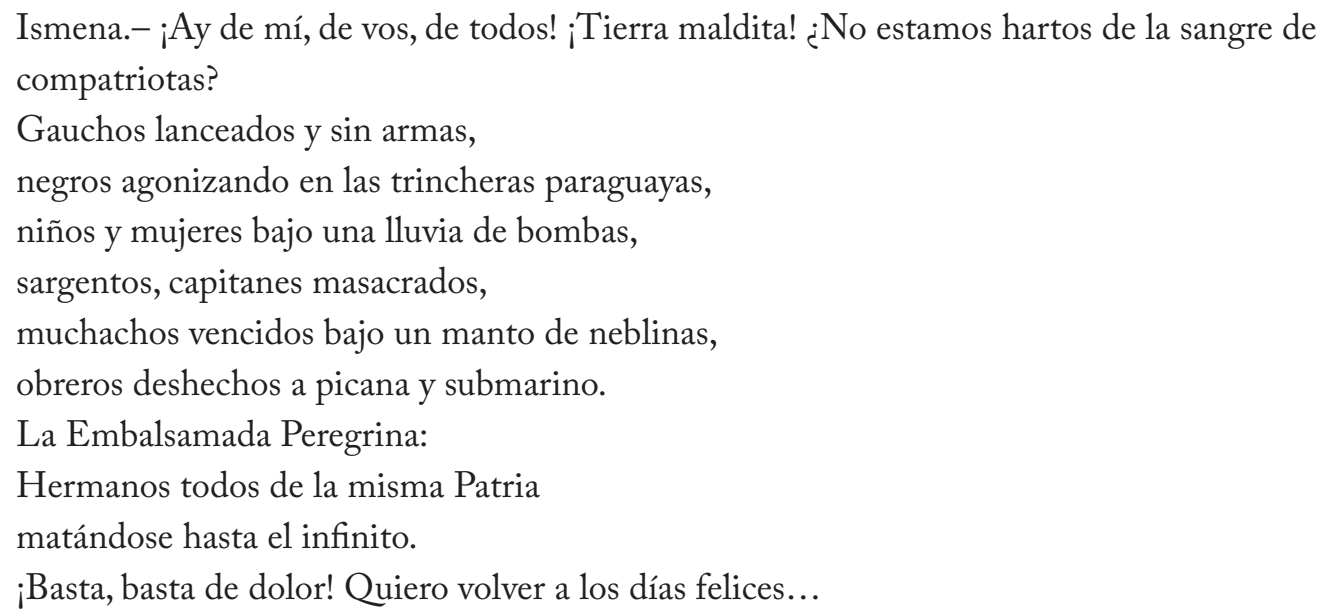

(Huertas, 2002, p. 25-26) 
En la obra de Huertas se enfatiza la oposición macho-hembra (ya presente en la tragedia de Sófocles) representada por las figuras de Creonte, que dicta la ley del hombre, y Antígona, que se opone porque sigue las leyes divinas. En los diálogos entre Creonte y Antígona, el tirano es consciente del poder que tiene en tanto gobernante y en tanto hombre, lo que se manifiesta en su discurso al construirse como "macho", "rey" o "Dios". Por otro lado, desprecia a la heroína por su condición de mujer y lo manifiesta de manera enfática con expresiones que buscan quitarle valor al discurso de Antígona, ella es la "loca”, "hembrita”, "guaranga":

Creonte.- Callate, loca.

Antígona.- Una loca con otro loco está hablando.

Creonte.- Te burlaste de mí dos veces: la primera, enterrando a tu hermano; la segunda, sintiendo orgullo por hacerlo. ¿Quién es el macho acá? ¿Quién la hembrita?

Antígona.- ¿Querés borrar la escritura de La Eterno?

Creonte.- Soy el rey de Buenos Aires.

(...)

Yo decido quién vive y quién muere.

Antígona.- Estás destruyendo un orden elemental. ¡Mierda!

Creonte.- ¡Cuidá la lengua! Te parecés a la guaranga, a la muñeca de los obreritos.

Antígona.- ¿Quién te creés que sos?

Creonte.- $¡$ Yo soy Dios en esta ciudad!

(Huertas, 2002, p. 39-40)

Pese a los intentos, por parte de Creonte, de rebajar a Antígona por su condición de mujer, ella no pierde el valor y su objetivo de denunciar los abusos del tirano.

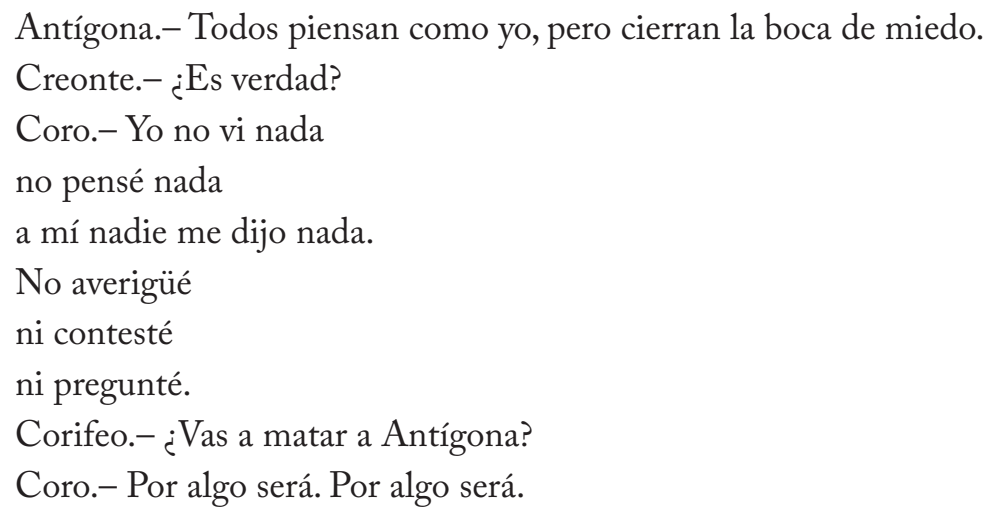

(Huertas, 2002, p. 44)

A través de las palabras del Coro se recuerdan varias expresiones que el receptor argentino asocia a uno de los discursos que circulaba en la época de la última dictadura militar que reflejaba una conducta pasiva en cuanto a lo que estaba sucediendo (era mejor no saber) y se buscaba una justificación de los abusos cometidos por el poder ("por algo será”).

Tanto en la tragedia griega como en el drama argentino el enfrentamiento contra los excesos de poder es llevado adelante por mujeres. En el caso del texto de Sófocles, Antígona se construye como una figura femenina que rebasa el radio de acción asignado tradicionalmente a la mujer, el oikos, 
para actuar en la esfera pública, propia de los hombres; en el drama argentino, se resalta la ruptura del modelo tradicional femenino que implica el acto de Antígona. De este modo, por contraste, se subraya la inactividad de quienes, pudiendo actuar, no lo hacen por temor a ser víctimas del poder despótico a pesar de la conciencia de estar frente a un hecho injusto.

El dramaturgo argentino incorpora en la obra a la Embalsamada Peregrina, personaje que está construido sobre la base de la figura histórica de Eva Perón:

Corifeo.- Cuerpo de treinta y nueve kilos: capilla ardiente, amores de embalsamador.

El Congreso intermitente de la Nación

o el Congreso de la Nación intermitente.

Mira desde atrás los estrenos

(matinée, vermouth y noche)

comedias, musicales y siempre el drama.

Marilyn, Rita Hayworth, Charles Boyer.

Sólo artistas acompañan su soledad de muerta.

(Huertas, 2002, p. 47)

Su presencia responde, sin duda, a su carácter de cadáver sin sepultura, lo que se conecta con la situación de Polinices, y se instaura, además, como metáfora de la historia del país.

Por otro lado, en su condición de mujer se identifica con Antígona en cuanto se rebela y denuncia los abusos sufridos por las todas las mujeres argentinas, de las más diversas condiciones, que su figura condensa. El personaje dice: "Mi cuerpo es el mapa del alma argentina" (Huertas, 2002, p. 47). En diálogo con el Coro, la Embalsamada Peregrina denuncia:

La Embalsamada Peregrina.- Mientras tanto,

una mujer morirá siempre

Llorarán miles y sufrirán todas.

Nosotras, las que luchamos día a día

alimentando hijos sin padres.

Nosotras, las que abrimos escuelas

e izamos la bandera.

Nosotras las mal paridas

las mal pagadas

las mal cogidas.

Nosotras las chinitas catamarqueñas

atravesadas vuelta y vuelta

en el altar del falo patrio.

Mochileras, prostitutas,

niñas ahogadas por el instinto macho.

Siempre habrá una hembrita

y su cuerpo abierto

tirada sobre el altar del falo patrio.

(Huertas, 2002, p. 58-59) 
En esta enumeración se mezclan hechos reales (como el caso de María Soledad Morales), con otros más generales del pasado pero que tienen aún resonancia en nuestro presente. La Embalsamada Peregrina condensa en un mismo ser la sensibilidad femenina, la pasión ferviente de una religiosidad mítica y popular y los ritos mortuorios desde la figura de la mujer que sabe gritar con valor la injusticia del hombre.

La heroína trágica, en la escena titulada "Adiós, Antígona”, identifica su suerte, su destino después de muerta, con el de la Embalsamada Peregrina, ante la posibilidad de sufrir lo mismo que padeció el cuerpo de Eva Perón, que fue embalsamado, ultrajado, robado. El corifeo confirma que, aunque el origen de cada una es distinto, el destino de ambas se asemeja:

Antígona.- ¿Por qué no acude a mí La Embalsamada Peregrina, con su lluvia de pétalos amarillos, con sus manos temblorosas de victorias?

Corifeo.- No era una diosa ni nacida de dioses la chinita. Pero las suertes se emparejan.

Antígona.- No se rían de mí. ¿Seré también peregrina? ¿Me tajearán el costado? ¿Meada y muerta?

(Huertas, 2002, p. 60-61)

En esta misma escena, la intervención del "Coro de hembras" es significativa, pues ellas también se identifican con el destino funesto de Antígona, el de una mujer enfrentada a las leyes de los hombres, unida por el amor fraterno a sus muertos, valiente a pesar del castigo que recibirá por su arrojo, desprestigiada por ese mundo dominado por el poder de los hombres:

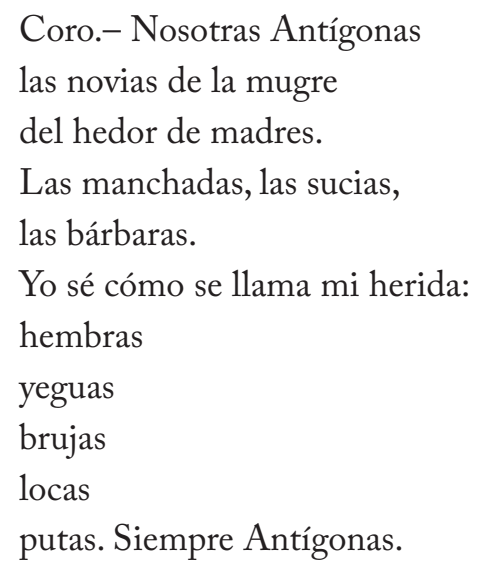

(Huertas, 2002, p. 62)

\section{A modo de conclusión}

Huertas se apropia del texto de Sófocles y lo sitúa en el Buenos Aires de principios del siglo XXI para reactualizar la dicotomía Antígona-Creonte, ampliando el núcleo trágico a través de la inclusión de personajes y referencias al nuevo contexto de producción; los que, imbricados a lo largo de todo el texto, constituyen una isotopía con un sentido político que permite revisar la historia del país signada por las luchas fratricidas y los muertos sin sepultura. 
Al discurso unívoco, emanado del poder tiránico, se opone la voz de Antígona, que se destaca tanto por encarnar una posición diferente que no responde a las coyunturas sociopolíticas sino a valores eternos, como por provenir de una mujer, a quien la sociedad asigna tradicionalmente un rol distinto.

El traslado de la tragedia griega a la Argentina contemporánea permite tratar una problemática de vieja raigambre, el tema del poder y las relaciones que en torno a él se entablan, con nuevas miradas. Pero lejos de constituir un simple traslado o de constatar la influencia de la obra de Sófocles, el texto del dramaturgo argentino adquiere nuevos significados acordes con los nuevos contextos, tanto de producción como de recepción. Como expresa De Pourcq: "The focus is no longer on the lasting influence of the ancient source but on the different meanings, functions and forces an ancient element acquires at the moment of reception" (2012, p. 221).

La tragedia de Huertas resignifica el modelo clásico porque, por un lado, produce un desplazamiento hacia la división en fuerzas antagónicas que ha caracterizado la historia de la Argentina y, por otro, porque la acción de Antígona es un símbolo de la búsqueda de las madres, hijas y hermanas de los muertos sin sepultura de la historia reciente del país.

Al hipotexto clásico se suman otros textos a los que apela el enunciador, como letras de tango, anuncios publicitarios, discursos políticos, poemas de Borges, frases populares del acervo cultural de la Argentina, que aparecen reformulados con distintas intencionalidades. Además de apelar a la competencia del lector, la presencia de estos intertextos le permite al autor ensayar nuevos modos de decir la realidad, siempre compleja y múltiple, dando cuenta del aporte del mundo antiguo al corpus cultural occidental, en general, y argentino, en particular.

\section{Referencias bibliográficas}

De Pourcq, M. (2012). Classical Reception Studies: Reconceptualizing the Study of the Classical Tradition. The International Journal of the Humanities, 9 (4), 219-225.

Grimal, P. (2005). Diccionario de mitología griega y romana. Buenos Aires, Paidós.

Hardwick, L. y Stray, C. (eds.) (2011). A companion to classical receptions. Oxford, Blackwell.

Huertas, J. (2002). Antígonas: linaje de hembras. Buenos Aires, Biblos.

Kitto, H. D. F. (1987). Los griegos. Buenos Aires, Eudeba.

Pinkler, L. (2002). La Antígona de Huertas: tragedia y tango. En Huertas, J., Antígonas: linaje de hembras. Buenos Aires, Biblos.

Pomeroy, S. (1987). Diosas, rameras, esposas y esclavas: Mujeres en la Antigüedad Clásica. Madrid, Akal.

Rohde, E. (1948). Psique. La idea del alma y la inmortalidad entre los griegos. México, Fondo de Cultura Económica.

Sófocles (1965). Tragedias: Antígona - Electra. Barcelona, Alma Mater.

Zohar, I. E. (1999). Teoría de los Polisistemas. Madrid, Arco Libros. 
*Claudia Elizabeth Lobo es Profesora en Letras egresada de la Facultad de Filosofía y Letras de la Universidad Nacional de Tucumán. Es Profesora Adjunta de Introducción a la Cultura Grecolatina y de Literatura Latina en la UNT. Es miembro del proyecto de investigación PIUNT "Relaciones de poder en la Roma antigua (siglos I a. C. y I d. C.). Representaciones y resignificaciones".

**Rolando Jesús Rocha es Licenciado en Letras por la Universidad Nacional de Tucumán. Es Profesor Adjunto de Lengua Griega y de Lengua Latina en la Universidad del Norte Santo Tomás de Aquino y Auxiliar Docente Graduado de Lengua y Literatura Griegas I y II en la Universidad Nacional de Tucumán. Es miembro del proyecto de investigación PIUNT "Relaciones de poder en la Roma antigua (siglos I a. C. y I d. C.). Representaciones y resignificaciones”.

RECIBIDO: 15/05/2021

ACEPTADO: 02/06/2021 